\title{
GENERALIZED LENTIGINOSIS: AN UNCOMMON PRESENTATION
}

M. Valluvan ${ }^{1}$, Divvya B ${ }^{2}$, P. Viswanathan ${ }^{3}$, P. V. S. Prasad ${ }^{4}$, P. K. Kaviarasan ${ }^{5}$

\section{HOW TO CITE THIS ARTICLE:}

M. Valluvan, Divvya B, P. Viswanathan, P. V. S. Prasad, P. K. Kaviarasan. "Generalized Lentiginosis: An Uncommon Presentation". Journal of Evolution of Medical and Dental Sciences 2014; Vol. 3, Issue 21, May 26; Page: 5813-5819, DOI: $10.14260 /$ jemds/2014/2667

ABSTRACT: A case of Generalized Lentiginosis is being documented for its rarity. A 27 years old congenitally deaf and mute, presented to our hospital with multiple asymmetrical brown-black to black colored macules involving all over the body sparing mucous membrane of oral cavity, palms and soles with melena. The patient was severely anemic on examination.

KEYWORDS: Lentigo, generalized lentiginosis.

INTRODUCTION: Lentigines (from the Latin "Lenz" meaning lens or 'small lentil') consist of flatpigmented macules on the skin and mucosa with irregular borders, discrete markings of different shades of brown and black and occurs due to increased proliferation of melanocytes in the dermo epidermal junction. Histopathology of lentigines reveal prominent epidermal thickening, basal cell hyperpigmentation associated with melanocyte hyperplasia and elongation of rete ridges. This histological feature is distinct from the melanocytes of freckles where normal number of melanocytes which are more pigmented due to increased melanin in basal keratinocytes (fig-1). ${ }^{1}$ While freckles are found almost exclusively on sun-exposed areas of the body, lentigenes may occur on all parts of the body and typically do not darken with sun exposure (as compared to freckles).

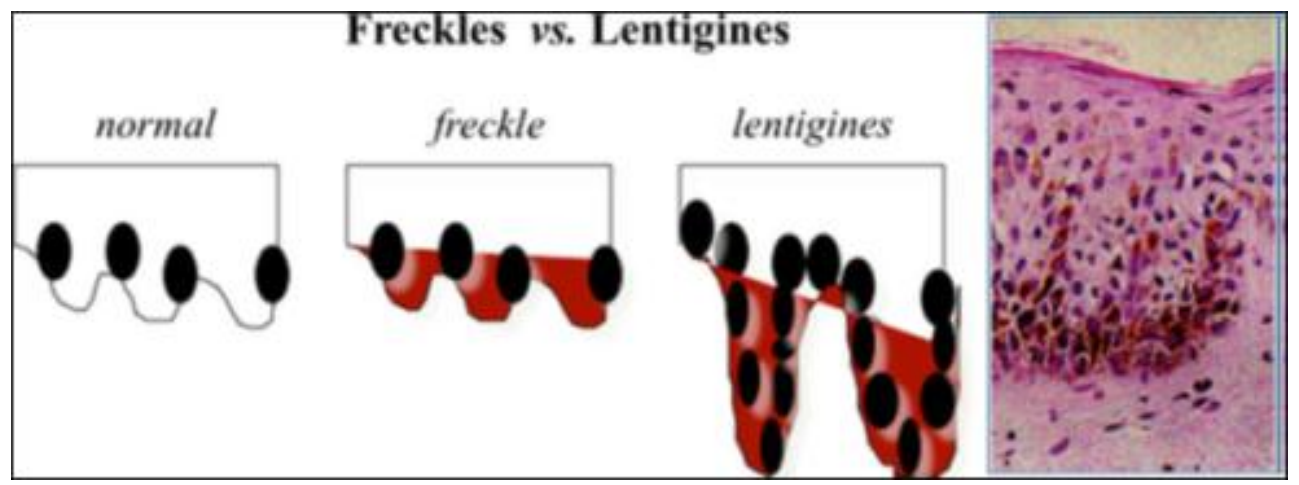

Figure 1

A wide range of drugs has been implicated, including azathioprine, ${ }^{2}$ infliximab, ${ }^{2}$ Prednisolone, ${ }^{3 i m m u n o s u p p r e s s i v e ~ d r u g s, ~}{ }^{4}$ cancer chemotherapy drugs, ${ }^{5}$ alefacept, ${ }^{2}$ etanercept, ${ }^{2}$ 6-mercaptopurine, ${ }^{6}$ and methotrexate. ${ }^{6}{ }^{7}$ Lentiginosis induced by psoralen UVA therapy, ${ }^{8}$ tacrolimus $^{9}$ and squaric acid dibutyl ester ${ }^{10}$ have been described in the literature.

A number of related disorders are also associated with lentigines and may be confused with Peutz- Jeghers syndrome (PJS), including Carney Complex (CNC), Laugier-Hunziker syndrome (LHS), Ruvalcaba- Myhre-Smith, Bannayan-Zonnana syndrome (BRRS), Cowden disease (CD), and LEOPARD/Noonan syndrome.11 
Serious internal anomalies are also observed in association with the following circumscribed lentiginosis syndromes: Peutz- Jeghers syndrome, Cronkbite-Canada syndrome, Bandler syndrome, and lentiginosis centrofacialis. ${ }^{12,}{ }^{13}$ In the Peutz-Jeghers syndrome perioral buccal lentiginosis is accompanied by polyposis of the intestine. There also seems to be an increased incidence of malignancy (7\%) involving mainly the gastrointestinal tract (stomach, duodenum, jejunum, colon, rectum, pancreas).

In Peutz- Jeghers syndrome, Key diagnostic features are hamartomatous polyps and mucosal hyperpigmentation. The characteristic pigmentation in PJS consists of dark brown-blue macules, but other lesions are not uncommon. The typical brown blue macules are commonly found on the border of the lips and oral and bowel mucosa, as well as on the palms and soles, eyes, nares, and peri-anal region. ${ }^{14}$ The pigmented macules are first visible in early childhood, and tend to fade in late adulthood. ${ }^{14}$

The Cronkhite-Canada syndrome is characterized by circumscribed lentiginosis of the extremities associated with lesions of the buccal mucosa, loss of hair, and polyposis of the intestine, the latter causing severe mal absorption. In the Bandler syndrome, Lentiginosis of the perioral and buccal mucosae is accompanied with hemangiomatosis of the intestine. Lentiginosis centrofacialis is a rare autosomal dominant syndrome, in which brownish or black spots appear as early as the first year of life.

Accompanying signs are as follows: spina bifida, hypertrichosis sacralis, kyphoscoliosis, absence of the upper middle incisor teeth, disorders of the eyebrows, and mental retardation."12

LEOPARD syndrome is an acronym that also describes the pattern of pigmentation found in this familial multiple lentigenes syndrome. The manifestations of this syndrome include Lentigines, Electrocardiographic conduction defects, Ocular hypertelorism, pulmonary stenosis, abnormal genitalia, retardation of growth, and sensorineural deafness. ${ }^{15}$ The diagnosis is established if multiple lentigines are present in association with at least two other features; if lentigines are absent, a firstdegree relative affected with LEOPARD syndrome and three of the other six features are needed for diagnosis. ${ }^{16,17}$

Lentigines are often the first clinical manifestation of in LEOPARD syndrome, and they are found primarily on the face and upper trunk, although rarely involve the oral mucosa, extremities, genitalia or conjunctiva. ${ }^{18}$ Lentigines in LEOPARD syndrome do not cross the vermilion border of the lips, a characteristic that distinguishes this disorder from CNC and PJS. It is unknown whether pigmented lesions in LEOPARD syndrome progress to malignancy ${ }^{19}$

The presence or absence of circumscribed or multiple lentiginosis accompanied by mucosal lesions is an important factor in the differential diagnosis of the disease called pigmentovascular phakomatosis. The pigmentovascular phakomatoses were first described by Ota in $1947^{20}$ and grouped by Hasegawa in1985.21

This syndrome is characterized by the following: nevus flammeus, nevus spilus, lentigines, blue nevus with or without nevus amenicus. "Phakos" is a Greek word meaning a "lentil" or figuratively "nevus." Phakomatosis is a collective term for several syndromes the cause of which is most likely genetic. During embryonic development, a mutation may be assumed to take place, affecting all three germinative layers and resulting in developmental anomalies of these layers, primarily of the ectoderm. ${ }^{13}$ 


\section{CASE REPORT}

CASE REPORT: A 27 years old congenitally deaf and mute male, presented to our hospital with multiple generalized brown-black to black pigmented macules of varying size $(<0.5 \mathrm{~cm})$ since birth. The skin lesions were distributed almost all parts of the body sparing the oral, genital mucous membranes, palms and soles. He had recurrent episodes of melena without hematemesis. The developmental milestones were appropriate for the age except speech (due to deafness).On general examination the patient was severely anemic.

A diagnosis of syndromic Lentiginosis was sought. Histopathological features shows features consistent with lentigines. Erythrocyte sedimentation rate, Liver function tests was within normal limits. Echocardiogram was normal. Ophthalmic assessment and fundus examination was normal. Endoscopy of upper gastro intestinal tract was suggestive of diffuse esophagitis.

HISTOLOGY: The epidermis showed varying degrees of atrophy with increased pigmentations presented in the keratin filling the crater (Fig- 4). There was hyperpigmentation in the basal layer and the pigmented cells were present in other layers of epidermis also. Basal cells showed vacuoles (Fig- 6). There were melanin pigment laded macrophages seen in the sub epidermal zone (Fig- 10). There was scattered inflammatory cell infiltration predominantly composed of lymphocytes. The dermis exhibited excessive collagenisation (Fig- 9).

DISCUSSION: Multiple benign lentigines developing as an isolated phenomenon are a common occurrence in healthy people. However, lentigines may be a component of rare but potentially serious hereditary multisystem syndromes such as LEOPARD, LAMB (Lentigines, Atrial myxomas, Myxoid neurofibroma, Blue naevi) and NAME (Naevus, Atrial myxoma, Myxoidneurofibroma, Ephelides) syndromes.

The term "generalized lentiginosis" is often reserved for such patients who have widespread lentigines without systemic abnormalities. ${ }^{22-26}$

Generalized Lentiginosis is a condition in which numerous lentigines, in no characteristic distribution, are widespread over the body; however, it should be noted that the term "generalized lentiginosis" is usually applied in the literature to cases in whom visible cutaneous signs are neither accompanied by mucosal involvement nor by systemic developmental anomalies of the central nervous system, the endocrine system, the mental development, or the bowels. ${ }^{27-29}$

In the syndromic Lentiginosis, the lentigines are present at birth or first appear early in life, and increase in number until adolescence. Eruptive Lentiginosis is the widespread occurrence of several hundred lentigines in a short period of time in the absence of systemic abnormalities. The absence of systemic abnormalities and the abrupt onset pattern differentiate eruptive Lentiginosis are seen in LEOPARD syndrome, Carney complex, and generalized Lentiginosis. ${ }^{30}$ Familial Lentiginosis syndromes are associated with an increased incidence of neural, endocrine, and mesenchymal tumors. ${ }^{1}$ Uhle and Norvell reported a family who had only generalized lentigines without systemic manifestations. ${ }^{22}$

In the present case, he was the only son born to non-consanguineous parents with lesions presented since birth with Deaf-mutism. There was no similar illness in their family. The final diagnosis of LEOPARD syndrome could not be made since the patient did not fulfill the minimum criteria of having at least two features. ${ }^{17,18}$ In this case other than congenital generalized lentiginosis, Deaf-mutism, esophagitis and melena no other specific clinical findings suggestive of lentiginosis 
syndromes available in the literature. Considering the clinical and histological findings and presence of severe anemia with melena with deterioration of the clinical condition may be suggestive of future malignancies of GI or Hematological which requires periodical followup which may help us to arrive at a complete diagnosis. Hence we report this case for its rarity and atypical presentations with classical histological findings which was challenging the clinician.

\section{EQUIPMENT USED:}

Nikon Coolpix-8400

$\mathrm{x}$-denotes the power of objective

Stain used - (H \& E)

\section{REFERENCES:}

1. Fitzpatrick TB, Wolff K (2008) Fitzpatrick's dermatology in general medicine, 7th edn. McGraw-Hill, New York.

2. Bovenschen $\mathrm{HJ}$, Tjioe $\mathrm{M}$, Vermaat $\mathrm{H}$ et al. Induction of eruptive benign melanocytic naevi by immune suppressive agents, including biologicals. Br J Dermatol 2006; 154: 880-4.

3. Woodhouse J, Maytin EV. Eruptive nevi of palms and soles. J Am Acad Dermatol 2005; 52: S96-100.

4. Alaibac M, Piaserico S, Rossi CR et al. Eruptive melanocytic nevi in patients with renal allograft: report of 10 cases with dermoscopic findings. J Am Acad Dermatol 2003; 49: 10202.

5. Hughes BR, Cunliffe WJ, Bailey CC. Excess benign melanocytic naevi after chemotherapy for malignancy in childhood. BMJ 1989; 299: 88-91.

6. Happle R, Koopman RJ. Acral nevi following chemotherapy. Hautartz1990; 41: 331-2.

7. Richert S, Bloom EJ, Flynn K, Seraly MP. Widespread eruptive dermal and atypical melanocytic nevi in association with chronic myelocytic leukemia: a case report and review of the literature. J Am Acad Dermatol 1996; 35: 326-9.

8. Abdel Naser MB, Wollina U, El Okby M, El Shiemy S. Psoralen plus ultraviolet. An irradiationinduced lentigines arising in vitiligo: involvement of vitiliginous and normal appearing skin. ClinExp Dermatol 2004; 29: 380-2.

9. Hickey JR, Robson A, Barker JN, Smith CH. Does topical tacrolimus induce lentigines in children with atopic dermatitis? A report of three cases Br J Dermatol 2005; 152: 152-4.

10. Tosti A, Piraccini BM, Misciali C, Vincenzi C. Lentiginous eruption due to topical immunotherapy. Arch Dermatol2003; 139: 544-5.

11. Marsh DJ, Stratakis CA. Hamartoma and Lentiginosis syndromes: clinical and molecular aspects. Front Horm Res 2001; 28: 167-213.

12. Dociu J, Galaction-Nitelea O, Sirjita N, et al. Centrofacial lentiginosis. Br J Dermatol 1976; 94: 39-43.

13. Korting GW. Dermatologie in Praxis und Klinik. Vol. 3. Stuttgart: Thieme Verlag, 1979: 36.

14. Tomlinson IP, Houlston RS. Peutz-Jeghers syndrome. J Med Genet 1997; 34: 1007-1011.

15. Gorlin RJ, Anderson RC, Blaw M. Multiple lentigenes syndrome. Am J Dis Child 1969; 117: 652662. 
16. Legius E, Schrander-Stumpel C, Schollen E, Pulles-Heintzberger C, Gewillig M, Fryns JP. PTPN11 mutations in LEOPARD syndrome. J Med Genet 2002; 39: 571-574.

17. Chong WS, Klanwarin W, Giam YC. Generalized Lentiginosis in two children lacking systemic associations: case report and review of the literature. Pediatr Dermatol 2004; 21: 139-145.

18. Abdelmalek NF, Gerber TL, Menter A. Cardiocutaneous syndromes and associations. J Am Acad Dermatol 2002; 46: 161-183; quiz 83-86.

19. Seishima M, Mizutani Y, Shibuya Y, Arakawa C, Yoshida R, Ogata T. Malignant melanoma in a woman with LEOPARD syndrome: identification of a germline PTPN11 mutation and a somatic BRAF mutation. Br J Dermatol 2007; 157: 1297-1299.

20. Ota M, Kawamura T, Ito N. Phakomatosis pigmentovascularis IV/A. Arch Dermatol 1985; 121: 651-655.

21. Hasegawa Y, Yasahara M. Phakomatosis pigmentovascularis IV/A. Arch Dermatol 1985; 121: 651-655.

22. Uhle P, Norvell SS Jr. Generalized lentiginosis. J Am Acad Dermatol 1988; 18: 444-7.

23. Arnsmeier SL, Paller AS. Pigmentary anomalies in the multiple lentigines syndrome. Is it distinct from LEOPARD syndrome? Pediatr Dermatol 1996; 13: 100-4.

24. Zahorcsek Z, Schneider I. Generalized lentiginosis manifesting through three generations. Int J Dermatol 1996; 35: 357-9.

25. Betti R, Pozzi M, Inselvini E, Pazzini C, Crosti C. Sporadic generalized lentiginosis without systemic involvement. Eur J Dermatol 1998; 8: 183-5.

26. Chong W-S, Klanwarin W, Giam Y-C. Generalized Lentiginosis in two children lacking systemic associations. Pediatr Dermatol 2004; 21: 139-45.

27. Selmanowitz VJ, Orentreich N, Felsenstein JM. Lentiginosis profusa syndrome (multiple lentiginosis syndrome). Arch Dermatol 1971; 104: 393-401.

28. Atherton DJ, Pitcher DW, Wells RS et al. A syndrome of various cutaneous pigmented lesions, myxoid neurofibromata, and atrial myxoma: the NAME syndrome. Br J Dermatol 1980; 103: 421-429.

29. Dociu J, Galaction-Nitelea O, Sirjita N, et al. Centrofacial lentiginosis. Br J Dermatol 1976; 94: 39-43.

30. Ortonne J, Bahadoran P, Fitzpatrick TB, Mosher DB, Hori Y. Hypomelanoses and hypermelanoses. In: Freedberg IM, Eisen AZ, editors. Fitzpatrick's Dermatology in General Medicine. 6th ed. Vol 2. New York: McGraw-Hill Medical Publishing; 2003. p. 863. 


\section{CASE REPORT}

\section{MACROSCOPIC PICTURE}

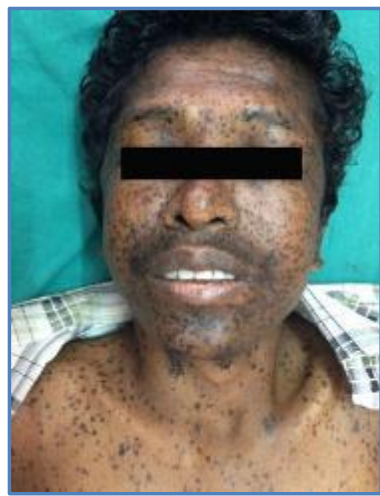

Figure 2

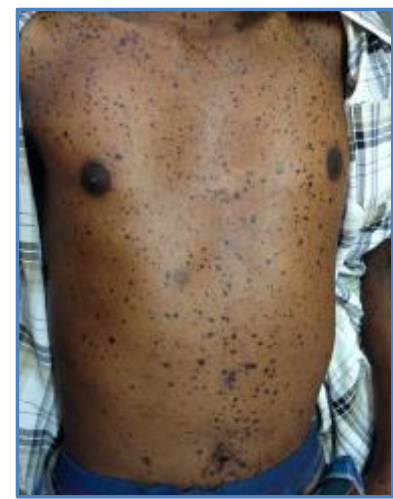

Figure 3

MICROSCOPIC PICTURES

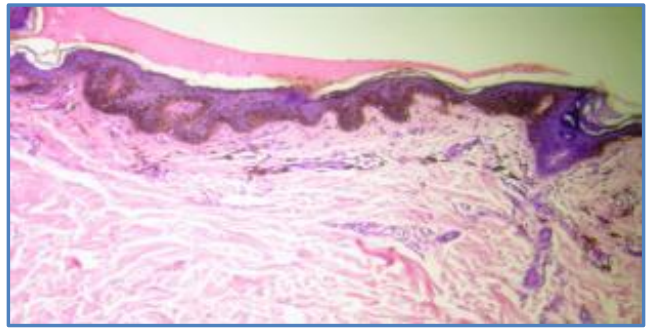

Figure 4: (H \& E)stained x4

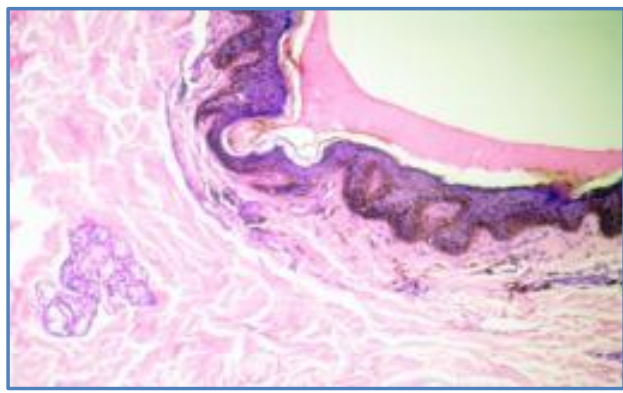

Figure 5: (H \& E) stainedx10

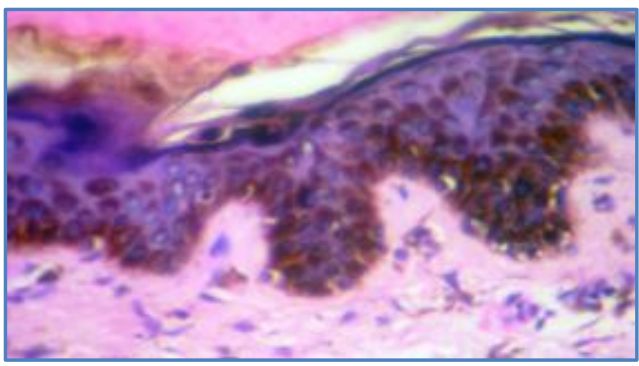

Figure 6: (H \& E) stained x10

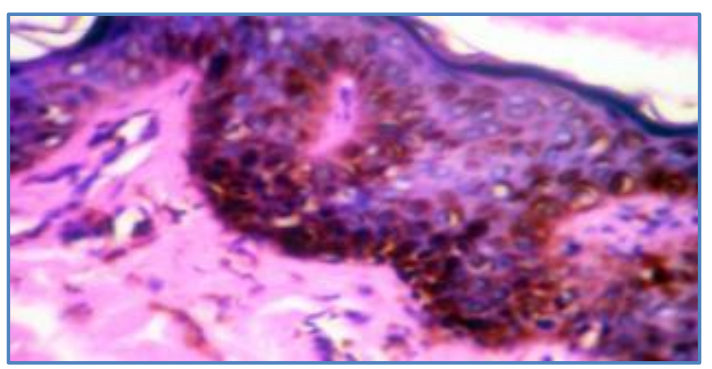

Figure 7: (H \& E) stainedx40 


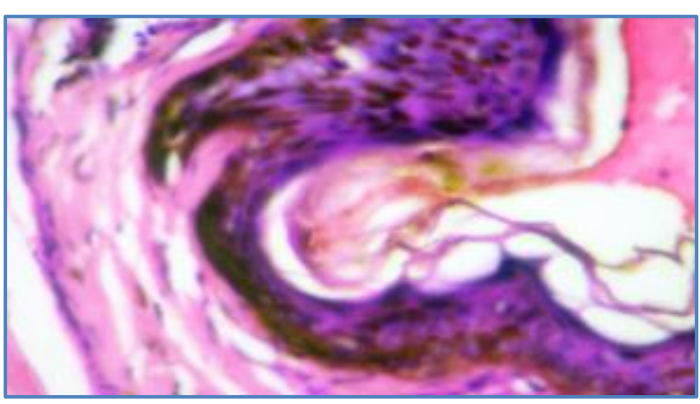

Figure 8: (H \& E) stained x40

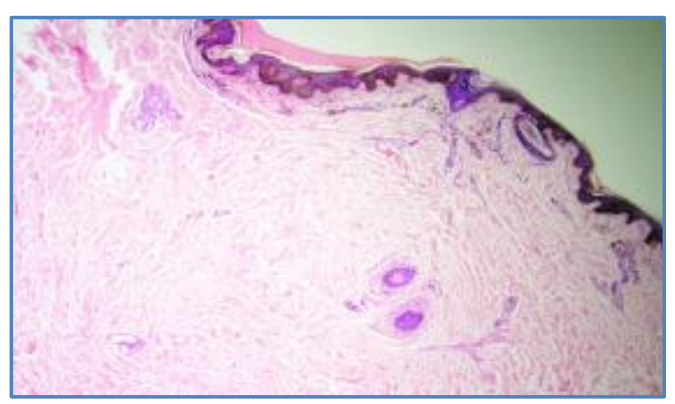

Figure 9: (H \& E) stained x4

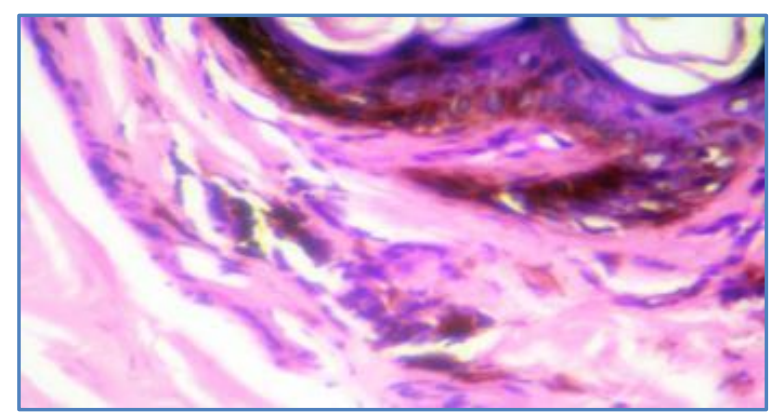

Figure 10: (H \& E) stained x 40

\section{AUTHORS:}

1. M. Valluvan

2. Divvya B.

3. P. Viswanathan

4. P. V. S. Prasad

5. P. K. Kaviarasan

\section{PARTICULARS OF CONTRIBUTORS:}

1. $1^{\text {st }}$ Year Post Graduate, Department of Pathology, Rajah Muthiah Medical College, Annamalai University.

2. $1^{\text {st }}$ Year Post Graduate, Department of Pathology, Rajah Muthiah Medical College, Annamalai University.

3. Professor, Department of Pathology, Rajah Muthiah Medical College, Annamalai University.

4. Professor, Department of Dermatology, Venereology and Leprosy, Rajah Muthiah Medical College, Annamalai University.
5. Professor, Department of Dermatology, Venereology and Leprosy, Rajah Muthiah Medical College, Annamalai University.

\section{NAME ADDRESS EMAIL ID OF THE CORRESPONDING AUTHOR:}

Dr. P. Viswanathan,

Professor, Department of Pathology,

Faculty of Medicine,

Rajah Muthiah Medical College,

Annamalai University,

Chidambaram-608002,

Tamilnadu, India.

Email: drpviswanathan2013@gmail.com

Date of Submission: 04/05/2014.

Date of Peer Review: 05/05/2014.

Date of Acceptance: 15/05/2014.

Date of Publishing: 26/05/2014. 